\title{
A Factorial Analysis on Organizational Power Construction — From the Perspectives of School Leaders in Taiwan
}

\author{
Mingchang Wu, Chenju Ko, Chihchieh Huang, and Wenlung Chang
}

\begin{abstract}
Organizational power exploitation and development has received broad attention from the fields of business world and educational settings in the last two decades. A series of previous studies individually revealed that organizational power was related to its members' intrapersonal factors and external ones, such as self concept, mental health, organizational trust, and manifest needs. However, these four factors concurrently rather than individually exist, in the realistic world, and make integrative instead of separate influences on organizational power. Therefore, curiosity occurs that how do these factors coexist and interact in the process of developing the sense of organizational power? A sample of $\mathbf{2 5 0}$ elementary school leaders were investigated employing five standard instruments with high reliabilities and validities. These data were analyzed, taking the path analysis and structural equation model analysis, to answer the research questions. Resultant imperative findings included: 1 . These five factors were disclosed to be coexistent with and interdependent on one another; 2 . Self-concept plays a fundamental factor to nurture their mental health, inspire their manifest needs, and facilitate their organizational trust in a spiral route; and 3. Individuals' organizational trust is the dominant factor manipulating the intensity of organizational power to school leaders while comprehensively considering all influential factors. These crucial findings conclusively instigated some suggestions to further enhance organizational power. Some ones also addressed research methods and rationales in future studies to build profound understanding on the development and improvement of organizational power in terms of theories and practices.
\end{abstract}

Index Terms-Organizational power, school leaders, intrapersonal factor structure.

\section{INTRODUCTION}

Organizational performance and administrative efficiency were approved to highly rely on the organizational power among its members [1]. Organizational power in the workplace keeps receiving intensive concerns from educational communities to enhance school achievement and teachers' performance [1], [2]. A series of studies consistently declared that organizational power was built with high relationships to its members' intrapersonal traits such as self-concept [3], mental health [4], and manifest needs [5], [6], besides their organizational trust [7]. These intrapersonal factors were approved to separately influence

Manuscript received April 2, 2015; revised June 23, 2015.

The authors are with the National Yunlin University of Science and Technology and Tzu Chi College of Technology, Taiwan (e-mail: wumc@yuntech.edu.tw, chenjuko@tccn.edu.tw, g9245703@gmail.com, uenlung@chsc.tw). the organizational power in the aforementioned studies. However, Bandura's Theory of Reciprocal Causation [8] seemed not fully support the single-factor effect on individual's perception development and, on the contrary, asserted the interactive and gradual effects of successive development among personal factors and the social environment. That is, those perspective factors reciprocally develop within interactive processes from the interior, such as self concept and mental health, to the exterior, such as organizational trust, and organizational power.

Curiosities emerged that how these four intrapersonal traits comprehensively influenced organizational power in terms of their influential paths and structural model; also if these influential factors created any interactive effect on the organizational power in educational settings. Consequently, this study, taking Bandura's Theory of Reciprocal Causation, was conducted to identify the factorial structure and influential paths of organizational power which has been asserted to be both directly and indirectly influenced by self-concept, mental health, manifest needs, and organizational trust.

\section{RESEARCH METHODS}

\section{A. Conceptual Framework}

This study was conducted to examine the hypothesized factorial structure of organizational power which might be both directly and indirectly influenced by team members' intrapersonal factors focusing on self-concept, mental health, positive thinking style, and emotional management in this study (Fig. 2).

\section{B. Research Instrument}

According to the research purposes, this study employed a survey questionnaire with 57 items adapted from the following five instruments separately for the five major constructs:

\section{1) Organizational power assessment}

The Organizational Power Assessment used in this study was revised for Taiwanese university scenarios on the basis of Medcof's research [9]. This revised assessment consists of 13 items within three sub-dimensions: Coercive power (5 items), Legitimate power (4 items), and Reward power (4 items). This assessment possessed a high reliability for overall (Cronbach's $\alpha=0.98$ ).

\section{2) Manifest needs assessment}

The Manifest Needs Assessment used in this study was 
also developed according to McClelland's Needs Theory (1987) and Murray's ideology (1938) consisting of 15 items within 3 sub-dimensions: Need for Achievement (5 items), Need for power (5 items), and Need for Affiliation (5 items). This assessment was testified with a high reliability for overall (Cronbach's $\alpha=0.89$ ).

\section{3) Organizational trust instrument}

The Organizational Trust Assessment used in the research was adopted from Cummings \& Bromiley's (1996) [10] Organizational Trust Inventory-Short Form including 12 items within three sub-dimensions: Keep commitments (4 items), Negotiate honestly (4 items), and Avoid taking excessive advantage (4 items). This assessment possessed a high overall reliability (Cronbach's $\alpha=0.91$ ).

\section{4) Self-concept construct}

The self-concept construct was assessed through the sub-dimension of Social Self-Concept (8 items) from Chen (1996). This instrument was validated with an appropriate reliability for overall (Cronbach's $\alpha=0.79$ ) and the sub-scale of Social Self-Concept (Cronbach's $\alpha=0.82$ ).

\section{5) Mental health construct}

The Mental Health in Short-Form Ware \& Sherbourne (1992) possesses 9-item instrument possessed an acceptable reliability (Cronbach's $\alpha=0.80$ ).

\section{Data Collection and Sample}

This study consequently surveyed 300 elementary school leaders as a sample, using the revised 57-item questionnaire, with their understanding and cooperation, and received 263 returned questionnaires after 2 times of follow-ups. Finally, this study took the 253 responses with complete and valid information, deleting 10 invalid ones, for the data analyses (valid returned rate $84.0 \%$ ). These sampled participants included male $(N=186 ; 73.52 \%)$ and female professionals $(N=67 ; 26.48 \%)$. Most of them obtained Master's degrees $(N=181 ; 71.5 \%)$.

\section{Data Analysis}

According to the research purposes and hypothesis examination, the collected data were statistically analyzed undertaking: 1) Pearson correlation analysis to identify the pairwise relationships among the factors; 2) Path coefficient analysis to separately examine the individual influential effect of each factor on another; and 3) Structural equation modeling analysis to further understand the influential paths and comprehensive structure of the five factors [11].

\section{RESEARCH FINDINGS}

\section{A. Reliability and Validity of the Instrument}

The reliability analysis revealed the Cronbach's alpha scores for the factors ranged from 0.80 to 0.83 (Table I), all exceeded the benchmark of 0.70 [12]. That is the research instrument had an acceptable internal consistency of items measuring the same construct. The Composite reliabilities (CR) values of the factors were between 0.66 and $0.87(>0.6)$ exhibiting a good internal consistency for each construct [13] The AVEs (all > the threshold of 0.5 ) approved this study had adequate convergent and discriminant validities [14]. Synthetically, this measurement was approved to be reliable and valid in this study.

TABLE I: RELIABILITIES AND VALIDITIES OF CONSTRUCTS

\begin{tabular}{lcccc}
\hline \hline Construct & Factor loading & Cronbach's $\alpha$ & CR & AVE \\
\hline $\begin{array}{l}\text { Organizational } \\
\text { power }\end{array}$ & $0.64 \sim 0.84$ & 0.82 & 0.85 & 0.67 \\
$\begin{array}{l}\text { Manifest needs } \\
\begin{array}{l}\text { Organizational } \\
\text { trust }\end{array}\end{array}$ & $0.60 \sim 0.90$ & 0.80 & 0.87 & 0.71 \\
$\begin{array}{l}\text { Self concept } \\
\text { Mental health }\end{array}$ & $0.53 \sim 0.94$ & 0.80 & 0.82 & 0.61 \\
\hline \hline$\quad N=253$ & $0.58 \sim 0.74$ & 0.83 & 0.82 & 0.61 \\
& & 0.81 & 0.66 & 0.57 \\
\hline
\end{tabular}

The factor analyses also resulted in the KMOs within the range between 0.81 and 0.86 with significance for the five constructs. This analysis also approved that the instruments possessed validities of good quality by overall variances above $50.22 \%$ [15].

\section{B. Relationships among the Five Traits}

The Pearson coefficient analyses also divulged that these four intrapersonal traits were all highly related with the organizational power and significantly related with one another $(p<$. 05) (Table II). These high relationships designated these intrapersonal traits might be coexistent with and interdependent on one another; each factor represented an autonomous and collective construct with high relations to organizational power [16].

TABLE II: PEARSON CORRELATION ANALYSIS RESULTS

\begin{tabular}{|c|c|c|c|c|c|}
\hline & Op & Mn & $\mathrm{Ot}$ & $\mathrm{Sc}$ & $\mathrm{Mh}$ \\
\hline $\begin{array}{l}\text { Organizational } \\
\text { power }\end{array}$ & 1.00 & & & & \\
\hline Manifest needs & $0.87 * * *$ & 1.00 & & & \\
\hline $\begin{array}{l}\text { Organizational } \\
\text { trust }\end{array}$ & $0.64 * * *$ & $0.56^{* * * *}$ & 1.00 & & \\
\hline Self concept & $0.58 * * *$ & $0.77 * * *$ & $0.52 * * *$ & 1.00 & \\
\hline Mental health & $0.53 * * *$ & $0.50 * * *$ & $0.55 * * *$ & $0.48 * * *$ & 1.00 \\
\hline \multicolumn{6}{|c|}{$\begin{array}{l}N=253 \\
(\mathrm{Op}) \text { Organizational power } \\
\text { (Mn) Manifest needs } \\
\text { (Ot) Organizational trust } \\
\text { (Sc) Self concept } \\
\text { (Mh) Mental health }\end{array}$} \\
\hline
\end{tabular}

\section{Structural Equation Modelling Analysis Results}

The SEM result finally supported the proposed influential paths and comprehensive structural model (Table III; Fig. 1) on the bases of the overall fit (Goodness of Fit $=434.081 /(\mathrm{d} f$ $=179)=2.425<3, p=0.000$, RMSEA $=0.075 ; \mathrm{GFI}=0.85(>$ $0.8)$, AGFI (Adjusted Goodness of Fit) $=0.806(>08)$. These index generally reached the recommended value, even the NFI (Normed Fix Index) $=0.807(<0.90)$, whereas NNFI (Non-Normed fit index) $=0.853(<0.9)$, did not authentically meet the standard value, it could barely approve structural equation modeling analysis [15]. In general, these indices were recognized to support the structural model. 
TABLE III: THE STANDARD INDEX ANALYSIS OF OVERALL MODEL FIT

\begin{tabular}{ccccc}
\hline \hline \multicolumn{1}{c}{ Test statistic } & $\begin{array}{c}\text { Standard } \\
\text { value }\end{array}$ & Test result & $\begin{array}{c}\text { Model fit } \\
\text { judgment }\end{array}$ \\
\hline & $\chi^{2}$ & $P \geqq 0.5$ & $\begin{array}{c}434.081 \\
(p=0.000)\end{array}$ & No \\
$\begin{array}{c}\text { Absolute fit } \\
\text { Index }\end{array}$ & GFI & $>0.80[12]$ & 0.85 & Yes \\
& AGFI & $>0.80$ & 0.806 & Yes \\
& RMSEA & $<0.08$ & 0.075 & Yes \\
\hline $\begin{array}{c}\text { Incremental fit } \\
\text { Index }\end{array}$ & NFI & $>0.90$ & 0.807 & No \\
\hline $\begin{array}{c}\text { Parsimonious } \\
\text { fit Index }\end{array}$ & $X^{2} / \mathrm{df}$ & $\leqq 3$ & 0.853 & Yes \\
\hline \hline$\quad N=253$ & $>0.90$ & 0.875 & Yes \\
\hline \hline
\end{tabular}

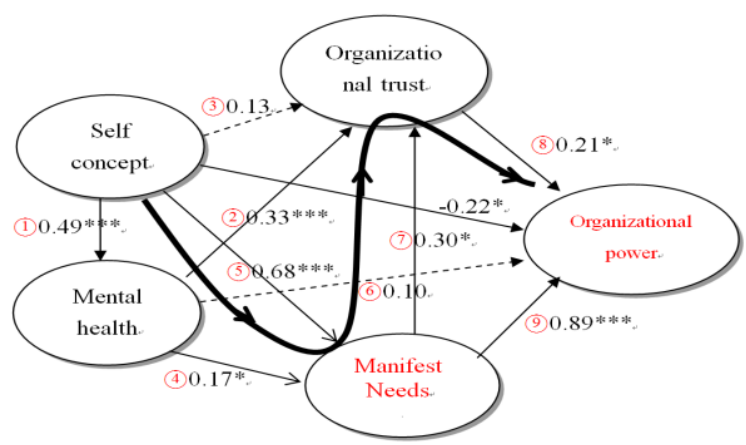

Fig. 1. The structural equation model of the all intrapersonal traits.

In order to further identify the influential paths of these four intrapersonal factors to organizational power, both the direct effects and indirect effects were computed to build a comprehensive structural model. As the results presented in the Table IV, the overall influential effect was the sum of direct effect of self concept (-.22) and all indirect effects through other factors $(0.074+0.61+0.043+0.034)$ on organizational power (.541)

The comprehensive analyses in this model indicated that self concept created multi-level indirect effects through other three related factors (.761) higher than its direct effect (-.22) and constansively created a synthetic influence on organizational power (.541). This comprehensive influence is close to the relationship between these factors (.58 in Table 2), but lower than its indirect effect. This fact implies that individuals' self concept creates a higher constansive impact through latent factors, provoking snowball effects, on their perspectives of organizational power than its single-factor effect in educational settings. The mediation effects of school leaders' manifest needs and organizational trust between their self concept and perspectives of organizational power were approved in the real workplace [17].

\section{Discussions, CONClusions, AND SUGGESTIONS}

This study, taking the viewpoints of Bandura's Theory of Reciprocal Causation purported to identify the influential paths and structural model of intrapersonal traits focusing on self-concept, mental health, manifest needs, and organizational trust, which were all approved to individually influence organizational power. These four intrapersonal traits were reconfirmed to be significantly related with each other, and analogously related with their organizational power. That is, these four constructs, as a symbiosis, should be coexistent with, interdependent on, and even interactively influence on one another. This finding also supported the arguments in previous studies [4] and endorsed the importance of these intrapersonal traits for school leaders to build their organizational power [18].

School leaders' self-concept, which was consistently recognized as a fundamental component of both intrapersonal factor and organizational involvement [19], was further identified to generate imperative impacts on the organizational power through circuitous mediation effects, higher than its unitary and individual effect, of their mental health, manifest needs, and then organizational trust [20]. These facts convincingly supported Bandura's reciprocal determinism and denoted that intrapersonal traits interactively developed their comprehensive and novel influential effects overwhelming any single-factor effect. This finding also supported Steele, Joseph, and Tager-Flusberg's declaration (2003) [21] that any single factor in the interactive processes might transform its original nature and effect into an inventive form as a result of the continuous interaction with environmental factors.

As Langfred's assertion (2000) [22], this study finally concluded that organizational power in educational settings was comprehensively developed through a series of dynamic transformation instigated by a variety of personal factors; organizational trust dominates the exploitation quality of organizational power. Synthetically, people's intention to build organizational power should reflect their high self-concept, manifest needs, and trust; not any single factor could individually facilitate this organizational power in the realistic ecological system of educational settings.

These conclusions both retrospectively and introspectively raised further contemplations and suggestions for future study: First of all, this study was conducted on the basis of school leaders' intrapersonal traits, seemly unintentionally overlooking their perspectives toward environmental factors such as interpersonal relationship and supervisors' leadership. External factors are therefore suggested to be further investigated in the future studies for in-depth understanding how people build organizational power considering the complex interaction of intrapersonal and external factors. Secondly, this study took subjective self-reported data which might vary from qualitative data from objective observers. Future studies might take out-group observers' perspectives to deeply investigate this issue.

\section{REFERENCES}

[1] D. J. Beal et al., "Cohesion and performance in groups: A meta-analytic clarification of construct relation," Journal of Applied Psychology, vol. 88, pp. 989-1004, 2003.

[2] A. E. Mark et al., "Coach-initiated motivational climate and cohesion in youth sport," Research Quarterly for Exercise and Sport, vol. 84, no. 3, pp. 373-383, 2013.

[3] J. Schnittker, "Psychological factors as mechanisms for socioeconomic disparities in health: A critical appraisal of four common factors," Social Biology, vol. 51, no. 1, pp. 1-23, 2004.

[4] R. Rios et al., "Neighborhood contexts and the mediating role of neighborhood social cohesion on health and psychological distress among hispanic and non-hispanic residents," The Society of Behavioral Medicine, vol. 43, no. 1, pp. 50-61, 2012. 
[5] S. A. McLeod. (2007). Maslow's hierarchy of needs. [Online]. Available: http://www.simply psychology.org/ maslow.html

[6] L. L. Moore et al., "Using achievement motivation theory to explain student participation in a residential leadership learning community," Journal of Leadership Education, vol. 9, no. 2, pp. 22-34, 2010.

[7] V. M. Ribiere and F. D. Tuggle, "The role of organizational trust in knowledge management: Tool \& technology use \& success," International Journal of Knowledge Management, vol. 1, no. 1, pp. $67-85,2005$.

[8] A. Bandura, "Human agency in social cognitive theory," American Psychologist, vol. 44, pp. 1175-1184, 1989.

[9] J. W. Medcof, "The organizational influence of the chief technology officer," R\&D Management, vol. 38, no. 4, pp. 406-420, 2008.

[10] L. L. Cummings and P. Bromiley, "The organizational trust inventory (OTI): Development and validation," Trust in Organizations, Thousand Oaks, CA: Sage, pp. 302-330, 1996.

[11] M. Brysbaert, Basic Statistics for Psychologists, UK: Palgrave, Co, 2011.

[12] J. C. Nunnally and I. H. Bernstein, Psychometric Theory, New York: McGraw-Hill, 1994.

[13] C. Fornell and D. F. Larcker, "Evaluating structural equation models with unobservable variables and measurement error," Journal of Marketing Research, vol. 18, no. 1, pp. 39-50, 1981.

[14] R. P. Bagozzi and Y. Yi, "On the evaluation of structural equation models," Academy of Marking Science, vol. 16, pp. 76-94, 1988.

[15] J. F. Hair et al., "Partial least squares structural equation modeling: Rigorous applications, better results and higher acceptance," Long Range Planning, vol. 46, no. 1-2, pp. 1-12, 2013.

[16] C. Eleras, "Path analysis," Encyclopedia of Social Measurement, vol. 3, pp. 25-30, 2005.

[17] K. Morgan, "Single-factor theories of insomnia - Handle with care," Age and Ageing, vol. 32, no. 2, pp. 123-124, 2003.

[18] M. S. Cole et al., "The workplace social exchange network: A multilevel, conceptual examination," Group and Organization Management, vol. 27, pp. 142-167, 2002.

[19] S. Y. Lu et al., "Factors related to depression during menopause: A study in Southern Taiwan," Journal of Nursing Research, vol. 17, no. 2, pp. 128-135, 2009

[20] C. B. Gibson, "Me and us: Differential relationships among goal-setting training, efficacy, and effectiveness at the individual and team level," Journal of Organizational Behavior, vol. 22, pp. 789-808, 2001.
[21] S. Steele et al., "Brief report: Developmental change in theory of mind abilities in children with autism," Journal of Autism and Developmental Disorders, vol. 33, pp. 461-467, 2003.

[22] C.W. Langfred, "The paradox of self-management: Individual and group autonomy in work groups," Journal of Organizational Behavior, vol. 21, pp. 563-585, 2000.

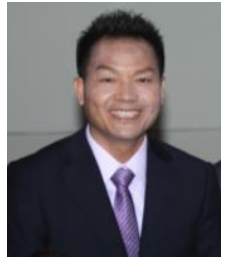

Mingchang $\mathbf{W u}$ is with a Ph.D. from Purdue University. He is a full professor in National Yunlin University of Science and Technology, Taiwan. He is dedicated to academic research in the field of university development and program evaluation.

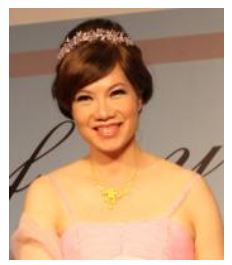

Chenju Ko is a senior lecturer of the Nursing Department at Tzu Chi College of Technology. She is working on her doctoral degree at Yangming Medical University

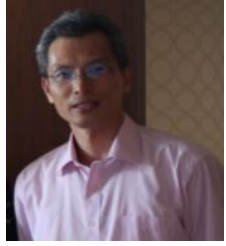

Chihchieh Huang is a $\mathrm{Ph} . \mathrm{D}$. student at National Yunlin University of Science and Technology in Taiwan emphasizing in design education.

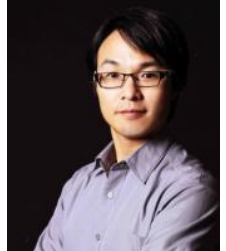

Wenlung Chang is a vocational high school teacher in the Department of Advertisement at National Chang-Hua Senior High School, majorly focuses on photography, design, video communication, and vocational and technological education. $\mathrm{He}$ is also a $\mathrm{Ph} . D$. student at National Yunlin University of Science and Technology in Taiwan emphasizing in design education. 